\title{
O CONTROLE JUDICIAL DA SELETIVIDADE CONSTITUCIONAL TRIBUTÁRIA E A INCIDÊNCIA DO ICMS SOBRE O CONSUMO DE ENERGIA ELÉTRICA NO BRASIL
}

\section{THE JUDICIAL REVIEW OF CONSTITUTIONAL TAX SELECTIVITY AND THE ICMS TAX ON ELECTRICAL ENERGY CONSUMPTION IN BRAZIL}

\author{
Recebimento: 24 maio 2019 \\ Aceitação: 11 jan. 2020 \\ Vinícius Simões Borges Espinheira Fonseca \\ Mestre em Direito \\ Afiliação institucional: Pontifícia Universidade Católica de Minas Gerais - PUC Minas - (Belo Horizonte, MG, \\ Brasil) \\ Lattes iD: http://lattes.cnpq.br/1003531121433155 \\ Email: espinheirafonseca@gmail.com \\ Edimur Ferreira de Faria \\ Doutor em Direito \\ Afiliação institucional: Pontifícia Universidade Católica de Minas Gerais - PUC Minas - (Belo Horizonte, MG, \\ Brasil) \\ Lattes iD: http://lattes.cnpq.br/3120858561560235 \\ Email: edimurfaria@hotmail.com
}

Como citar este artigo / How to cite this article (informe a data atual de acesso / inform the current date of access):

FONSECA, Vinícius Simões Borges Espinheira; FARIA, Edimur Ferreira de. O controle judicial da seletividade constitucional tributária e a incidência do ICMS sobre o consumo de energia elétrica no Brasil. Revista da Faculdade de Direito UFPR, Curitiba, v. 65, n. 3, p. 37-58, set./dez. 2020. ISSN 2236-7284. Disponível em: https://revistas.ufpr.br/direito/article/view/67065. Acesso em: $31 \quad$ dez. $2020 . \quad$ DOI: http://dx.doi.org/10.5380/rfdufpr.v65i3.67065.

\section{RESUMO}

O presente trabalho tem por objetivo principal o estudo do princípio constitucional da seletividade tributária estabelecido para o imposto sobre operações relativas à circulação de mercadorias e sobre prestações de serviços de transporte interestadual, intermunicipal e de comunicação (ICMS) pela Constituição brasileira de 1988, visando a elucidar as questões atinentes à incidência do referido imposto sobre o consumo de energia elétrica no Brasil e estabelecer os limites do controle judicial sobre a forma segundo a qual o ente tributante competente interpreta e aplica, na prática, a referida norma. Para alcançar esse objetivo, adota-se como metodologia de trabalho a consulta bibliográfica e a análise tanto da legislação, em particular a do estado de Minas Gerais, quanto da jurisprudência do Supremo Tribunal Federal acerca do tema referido. Ao fim, a conclusão alcançada foi a de que, no Estado Democrático de Direito brasileiro, o Poder Judiciário pode e, ademais, deve controlar atos normativos expedidos em torno de conceitos jurídicos indeterminados, como o da seletividade tributária, no cumprimento de seu papel institucional na ordem jurídica. 


\title{
PALAVRAS-CHAVE
}

ICMS. Seletividade constitucional tributária. Energia elétrica. Poder discricionário. Controle judicial.

\begin{abstract}
The present paper aims to analyse the constitutional principle of tax selectivity established by the Brazilian Constitution of 1988 for the tax on the circulation of goods, interstate and intercity transportation and communication services (ICMS for its Portuguese initials), in order to elucidate some issues related to its incidence on electrical energy consumption in Brazil, as well as to establish the limits of the judicial review over the way in which the competent taxing entity interprets and applies, in practice, the aforementioned rule. To reach this objective, a bibliographical review, and an analysis of the legislation, in particular that of the state of Minas Gerais, and the jurisprudence of the Brazilian Supreme Federal Court on this subject have been used as working methodology. In the end, the conclusion reached was that, under the Brazilian democratic rule of law, the Judiciary can and ought to review all normative acts issued about indeterminate legal concepts, such as the tax selectivity, in the fulfilment of its institutional role in the legal order.
\end{abstract}

\section{KEYWORDS}

ICMS. Constitutional tax selectivity. Electrical energy. Discretionary power. Judicial review.

\section{INTRODUÇÃO}

No Brasil, a tributação incidente sobre o consumo, cujo exercício compete, por força do texto constitucional de 1988, à União, aos estados, ao Distrito Federal e aos municípios, pode se dar por intermédio de tributos como, por exemplo, os impostos sobre operações relativas à circulação de mercadorias e sobre prestações de serviços de transporte interestadual, intermunicipal e de comunicação (ICMS), sobre produtos industrializados (IPI) e sobre serviços de qualquer natureza (ISSQN).

Previsto no art. 155, inciso II, da Constituição da República como sendo da competência tributária privativa dos estados federados e do Distrito Federal, o ICMS incide sobre a circulação comercial de mercadorias, ou daquilo que a mercadorias tenha sido equiparado pelo Direito, como é o caso da energia elétrica. Além de definir as hipóteses de incidência do ICMS, a Constituição prevê, em seu art. 155, § $2^{\circ}$, inciso III, que o referido imposto será seletivo em função da essencialidade da mercadoria (BRASIL, 1988).

O presente estudo cuida da controvérsia envolvendo a classificação da energia elétrica visando à concretização da seletividade relativa ao ICMS incidente sobre ela, conforme a sua disciplina constitucional que, ao mesmo tempo que outorga a competência tributária aos estados e ao Distrito Federal, impõe-lhes limitação no tocante à fixação de alíquotas diferenciadas para determinadas mercadorias. 
Esclarece-se, de pronto, que o uso do termo estado no presente estudo refere-se tanto a estado, ente federado, quanto a dois de seus três poderes, a saber, o Legislativo e o Executivo, aos quais competem, respectivamente, a função legislativa e a função administrativa. Não se incluiu a função jurisdicional, porque apenas as duas primeiras funções, e não a última, relacionam-se diretamente com a fixação de alíquotas como mecanismo de uma tributação seletiva, conforme exigida pela Constituição da República de 1988.

O problema posto pelo presente estudo corresponde à tributação, pelo ICMS, sobre o consumo de energia elétrica, porquanto há necessidade de ratificar a força normativa da Constituição da República no tocante à seletividade da tributação na modalidade de ICMS, de modo que o impacto de sua incidência, mormente sobre as classes econômicas mais baixas, seja reduzido e se adeque à exigência igualmente constitucional da capacidade contributiva.

Os objetivos do presente estudo são, pois, (i) examinar o princípio da seletividade tributária estabelecido para o ICMS pela Constituição da República, visando a elucidar as questões atinentes à incidência do referido imposto sobre o consumo de energia elétrica no Brasil, e (ii) verificar a possibilidade de controle judicial da interpretação e da aplicação da referida norma pelo Estado, seja o Estado legislador, seja o Estado administrador, adotando, na prática, a título de exemplo, a legislação pertinente do estado de Minas Gerais.

A fim de realizar os objetivos propostos, utiliza-se no presente trabalho, de metodologia que consiste fundamentalmente na consulta bibliográfica e na análise tanto da legislação como da jurisprudência do Supremo Tribunal Federal (STF) sobre o tema em questão.

O artigo procura enfrentar o problema da observância à seletividade constitucional tributária no momento da instituição do ICMS, pelos estados federados, para tributar determinados serviços e mercadorias em função de sua essencialidade. A hipótese é de que o mandamento constitucional não tem sido devidamente observado pelas legislações do referido imposto estadual tais como atualmente postas.

\section{A TRIBUTAÇÃO DO CONSUMO E O IMPOSTO SOBRE OPERAÇÕES RELATIVAS À CIRCULAÇÃO DE MERCADORIAS E SOBRE PRESTAÇÕES DE SERVIÇOS}

A relevância da tributação enquanto principal instrumento de financiamento estatal, especialmente a partir da consolidação do Estado fiscal, é inquestionável (COÊLHO, 2015, p. 34; SCHOUERI, 2018, p. 17-32). A tributação permite que o Estado participe do sucesso econômico da 
iniciativa privada, de modo a obter os recursos de que necessita para satisfazer os seus deveres para com a sociedade e necessários para o seu funcionamento.

Nada obstante, igualmente inquestionável é o fato de que o exercício do poder estatal de tributar intervém nos direitos fundamentais. Os direitos e garantias fundamentais dos contribuintes são especializações dos direitos humanos no campo tributário que se consubstanciam nas limitações constitucionais ao poder tributário (BALEEIRO, 2010, p. 28). Em assim sendo, esses direitos precisam de constante proteção e, no Estado Democrático de Direito, essa proteção decorre da garantia de eficácia dos princípios constitucionais (KIRCHHOF, 2016, p. 13).

A tributação do consumo, uma forma de tributação indireta, existe há muito tempo. O consumo dos indivíduos tem sido tributado desde a Antiguidade, incidindo seletivamente sobre alguns produtos específicos, como o sal e a carne. Em sintonia com o avanço do tempo, a tributação passou a alcançar o consumo geral, podendo ser monofásica, ocorrendo apenas no momento do consumo final, que se dá com a venda da mercadoria, ou plurifásica, incidindo ao longo de todo o ciclo produtivo que se completa com o consumo final. Por isso, a tributação do consumo é considerada “uma das formas mais complexas e completas de tributação existentes” (SILVEIRA, 2009, p. 333).

No Brasil, a tributação incidente sobre o consumo, repartida constitucionalmente entre a União, os estados, o Distrito Federal e os municípios, dá-se por intermédio de tributos indiretos, como, por exemplo, o ICMS, o IPI e o ISSQN.

Sinteticamente, a distinção entre tributos diretos e indiretos reside na possibilidade de transferência do seu encargo a outrem que não integra a relação jurídico-tributária na qualidade de sujeito passivo. No que concerne ao presente estudo, considerando a incidência sobre o consumo, quem suporta o encargo tributário representado pelo ICMS é o consumidor final, na medida em que o valor relativo a tal imposto encontra-se embutido no preço da mercadoria.

Previsto no artigo 155, inciso II, da Constituição da República, como sendo da competência tributária privativa dos estados federados e do Distrito Federal (BRASIL, 1988), o ICMS é o principal imposto brasileiro, em termos de arrecadação, sobre o consumo. De acordo com a Receita Federal do Brasil (RFB), a arrecadação do ICMS pelos estados e pelo Distrito Federal foi, em 2016, de R\$ 412.856.990.000.000, o que representa 20,37\% de toda a arrecadação tributária no País e 6,60\% do Produto Interno Bruto brasileiro (BRASIL, 2017).

De acordo com a Constituição da República em vigor, o ICMS incide sobre a circulação de mercadorias, inclusive importadas; sobre a produção, a circulação, a distribuição, o consumo e a importação de lubrificantes e combustíveis líquidos e gasosos, bem como de energia elétrica; sobre a 
prestação de serviços de comunicação; sobre a prestação de serviços de transporte interestadual e intermunicipal; e, por último, sobre a extração, a circulação, a distribuição e o consumo de minerais.

Em suma, o ICMS incide sobre a circulação comercial de mercadorias - ou daquilo que a mercadorias foi equiparado pelo Direito - para o consumo.

A Constituição, porém, não se limita a definir as hipóteses de incidência do referido imposto estadual e distrital. Ela dispõe, ainda, sobre as características fundamentais do ICMS, as quais devem ser observadas pela legislação complementar e pela legislação interna dos entes federados na sistematização do ICMS.

Entre as características constitucionais que delineiam a base do ICMS, encontra-se o objeto do presente estudo, a saber, a seletividade, conforme o art. 155, § $2^{\circ}$, inciso III, da Constituição (BRASIL, 1988), relativa à tributação da energia elétrica, que é equiparada a coisa móvel, integrando a hipótese de incidência do referido imposto (COÊLHO, 2015, p. 316).

Na medida em que o ICMS se relaciona com a tributação do consumo, faz-se mister notar duas qualidades que lhe são inerentes, uma positiva e outra negativa, ambas decorrentes do fato de que, a rigor, a incidência não se dá sobre a mercadoria, mas, sim, sobre a renda que se manifesta no ato de consumo dessa mercadoria. Luís Eduardo Schoueri (2018, p. 416) ilustra a questão:

É comum imaginar-se que um tributo incide sobre um produto. Afinal, é no ato de consumo que se dá a tributação e alíquota e a base de cálculo se fixam a partir do produto e seu preço. Essa aproximação, conquanto simples, não é satisfatória. De um ponto de vista econômico, o que se busca não é o valor do produto, mas a renda do consumidor. Por exemplo, uma mesma garrafa de água mineral tem preços bastante distintos se a venda se dá num supermercado, numa mercearia ou num restaurante luxuoso. O produto é o mesmo, mas o preço é diverso. Fosse o produto o foco da tributação, então não se justificaria diferença. Esta se dá porque, em verdade, o que se tem são três atos de consumo, pelos quais três pessoas diferentes empregam sua renda. $\mathrm{O}$ consumidor no restaurante empregará maior parcela de sua renda, se comparado aos demais. É essa renda que será tributada.

Desse modo, ao mesmo tempo que a tributação do consumo permite captar a renda não declarada, ela apresenta efeito regressivo. Isso se deve ao fato de que o consumo de mercadorias e serviços não reflete, necessariamente, a renda do contribuinte e, assim, o impacto do ônus tributário se reduz à razão inversa da renda do contribuinte. Entretanto, a imposição do princípio da seletividade, que implica a utilização de alíquotas menores para a tributação de produtos de primeira necessidade, representa uma forma de reduzir o referido efeito deletério.

Tal constatação apenas contribui para aumentar ainda mais a importância da seletividade no contexto brasileiro, na medida em que, se eficaz, esta regra pode operar para corrigir ou, ao menos, amenizar a regressividade em questão (SCHOUERI, 2018, p. 419-423) e, demais disso, servir como 
"parâmetro de preservação da neutralidade econômica sobre a renda das classes mais baixas" (SILVEIRA, 2009, p. 114), impedindo que essas sofram um impacto econômico maior.

\section{O PRINCÍPIO CONSTITUCIONAL DA SELETIVIDADE TRIBUTÁRIA}

No Direito, os princípios constitucionais organizam e tornam coerentes as estruturas normativas do sistema jurídico. Um desses princípios é o da seletividade tributária, o qual está previsto, de forma expressa, na Constituição da República de 1988.

O princípio da seletividade, no sistema constitucional tributário brasileiro, foi instituído como obrigatório para o IPI e facultativo para o ICMS (COÊLHO, 2015, p. 326; SCHOUERI, 2018, p. 416; SILVEIRA, 2009, p. 160; TORRES, 2014, p. 332). Os art. 153, inciso IV, § 3º inciso I, e 155, inciso II, $\S 2^{\circ}$, inciso III, da Constituição da República, respectivamente estabelecem:

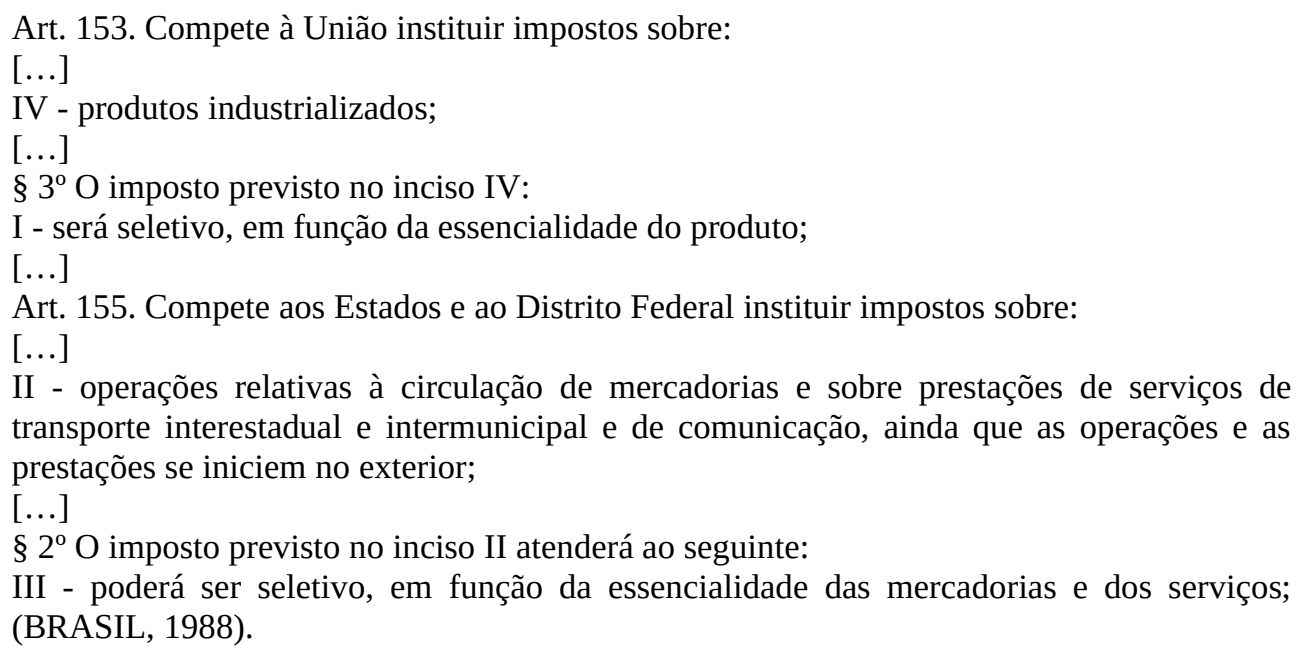

Conforme já exposto, o presente estudo, em razão de seu objetivo, concentra-se na seletividade relativa ao ICMS incidente sobre a comercialização de energia elétrica. No âmbito do sistema de repartição das competências tributárias entre os entes federados, o princípio da seletividade consiste em regra que impõe aos estados e ao Distrito Federal limitação no tocante à fixação de alíquotas diferenciadas para certas espécies de mercadorias (SILVEIRA, 2009, p. 160).

Considerado decorrência do princípio da capacidade contributiva (TORRES, 2014, p. 332), ao qual visa a atender (BALEEIRO, 2013, p. 659), o princípio da seletividade tributária requer que as alíquotas dos impostos a ele submetidos variem em função dos produtos, e tão somente deles, sob pena de contribuir para o aumento de desigualdades sociais cuja redução consiste em um dos objetivos fundamentais da ordem constitucional vigente (SCHOUERI, 2018, p. 214). 
Com efeito, conquanto pago pelos comerciantes, contribuintes de direito, na medida em que o ICMS é repassado aos consumidores finais, contribuintes de fato, a capacidade contributiva destes é que deve ser aferida no momento da incidência do imposto, por meio da manifestação de riqueza que demonstram ter com a aquisição da mercadoria para o consumo, a fim de que seja cumprido o princípio da capacidade contributiva (BALEEIRO, 2013, p. 660), constante, de forma explícita, no art. 145, § $1^{\circ}$, da Constituição da República (BRASIL, 1988).

Todavia, como a lei não pode conhecer a totalidade dos consumidores finais em suas respectivas individualidades (BRASIL, 1988), muito menos aprioristicamente, a Constituição da República previu a seletividade como um mecanismo para assegurar que a incidência tributária recaia sobre aqueles que devem suportar o encargo tributário, em consonância, ao menos em tese, com a exigência constitucional de respeito à capacidade econômica para contribuir com dinheiro para o custeio das despesas públicas.

Em uma de suas notas de atualização à obra de Aliomar Baleeiro, Misabel de Abreu Machado Derzi ilustrou essa realidade. Embora o exemplo por ela dado trate do IPI, ele se mostra plenamente adequado à realidade particular do ICMS, motivo pelo qual convém ora reproduzi-lo, in litteris:

Não podendo conhecer os consumidores, em escala de milhões, o legislador, olhos postos no princípio da capacidade contributiva, ao utilizar o princípio da seletividade, grava menos com o IPI os artigos essenciais. Justiça imperfeita, mas ainda justiça, pois José compra açúcar tanto quanto Simonsen, pelo mesmo preço pagando o mesmo IPI agregado ao preço. Em compensação, José não compra caviar mais tributado. Em suma, açúcar é essencial para todos em todo o território nacional. Para os pobres, principalmente para eles, em qualquer região do país, o preço do açúcar é essencial (BALEEIRO, 2013, p. 492).

Ao Estado é prescrita a observância ao princípio da seletividade em função da essencialidade dos produtos, a fim de que o exercício do poder de tributar seja válido, isto é, configure-se o "bom exercício” da competência constitucionalmente outorgada (BALEEIRO, 2010, p. 33). Afinal, o Estado deve sempre perseguir a solução que melhor atenda à finalidade do Direito, agindo nos limites do espaço que lhe é conferido pelo próprio Direito para tanto (FARIA, 2016, p. 133).

Assim, observar a seletividade significa que o Estado graduará a incidência do ICMS na razão inversa da necessidade e da utilidade da mercadoria e na razão direta de sua superfluidade para o consumo popular. Ricardo Lobo Torres traduz o referido comando constitucional da seguinte maneira: “A essencialidade admite graduação, de modo que a alíquota ou não existirá, quando o produto se tornar absolutamente essencial para atender às necessidades primárias, ou será fixada em escala ascendente na proporção em que menor for a sua utilidade social” (TORRES, 2014, p. 333). 
Diante de um conceito indeterminado, a margem de livre apreciação não é um dado apriorístico, mas, sim, um que deve ser esquadrinhado na contextura da norma em apreço e nos limites da ordem jurídica (BINENBOJM, 2017, p. 88).

Desse modo, é prudente reconhecer o acerto de Sacha Calmon Navarro Coêlho quando ratifica essa noção no tocante ao tema ora em análise, in litteris, “o conceito de mercadoria supérflua não fica ao alvedrio do legislador. Adotada que seja a seletividade, tem o contribuinte o direito de provocar o Judiciário para que declare, à luz de critérios técnicos e dos aspectos sociais da Nação, se esta ou aquela mercadoria é supérflua” (COÊLHO, 2015, p. 326).

Pode-se, porventura, questionar por que o constituinte não estabeleceu a seletividade em termos vinculados, isto é, por que não estabeleceu as alíquotas em que ela consubstanciar-se-ia de antemão, assegurando, desde logo, a única solução capaz de satisfazer o interesse público que deverá inspirar a positivação da norma pelo legislador estadual.

Em primeiro lugar, tratando-se de uma regra vinculada ao exercício do poder de tributar, o qual consiste em uma competência constitucional, o seu exercício não é obrigatório. Em outros termos, o Estado não é obrigado a tributar no limite de sua competência constitucionalmente outorgada, de modo que ela se esgote.

Em segundo lugar, diante da multiplicidade de materialidades (fatos da vida) que podem se sujeitar à tributação pelo ICMS, a depender de quais delas sejam objetivo de efetiva tributação pelo referido imposto, oferecer aprioristicamente a melhor solução seria inconveniente para o próprio interesse público que o Direito pretendeu que fosse satisfeito por intermédio da seletividade.

No tocante à seletividade do ICMS, de acordo com a essencialidade do objeto de sua incidência, o Estado, seja o Estado legislador, seja o Estado administrador, não dispõe do poder de escolher livremente ou, ainda, discricionariamente a forma pela qual concretizá-la. Essa limitação do campo de liberdade do Estado é uma decorrência evolutiva do aprimoramento do Estado de Direito (FARIA, 2016, p. 144). Nesse sentido, Ricardo Lobo Torres (2014, p. 338) afirma inequivocamente que:

[...] a discricionariedade legislativa na determinação da seletividade em função da essencialidade do produto encontra dois óbices de natureza constitucional:

a) não poderá introduzir incidência regressiva, tributando por alíquotas maiores os produtos mais necessários ao consumo coletivo;

b) não poderá discriminar entre produtos iguais com base em critério desvinculado da essencialidade do consumo. 
Cumpre ressaltar que, tratando-se de um conceito jurídico indeterminado, a seletividade se vincula a um significado do que deve ser, o qual acompanha a evolução da sociedade e, portanto, pode e deve variar no tempo e no espaço, de modo que o que é essencial hoje pode não o ser amanhã.

De todo modo, para elidir quaisquer dúvidas acerca da essencialidade da energia elétrica enquanto mercadoria tributada pelo ICMS, considere-se, desde já, a definição de bens de primeira ordem oferecida por Ricardo Lobo Torres (2014), para quem seriam “não só os que são indispensáveis para o sustento, mas todos os que o costume do país considera indigno para as pessoas que não os possuírem, mesmo as das classes mais baixas” (TORRES, 2014, p. 336). Por isso, tomando as palavras de Luís Eduardo Schoueri (2018, p. 420), afirma-se que:

Causa estranheza, daí, que se tribute a energia elétrica de modo mais elevado que outros itens, tendo em vista que seu consumo é imprescindível. No mesmo sentido, a telefonia pré-paga, hoje item de consumo generalizado, não justifica tributação acentuada. No mais das vezes, o que se encontra é uma tributação baseada em critérios de conveniência, não de justiça. Além de imediata agressão ao mandamento constitucional que impõe a Seletividade, o tratamento arbitrário que hoje se confere às alíquotas dos tributos sobre o consumo implica incrementarse o já regressivo tributo sobre o consumo.

A Constituição da República estabelece uma série de finalidades a serem alcançadas pelo Estado, a fim de que este satisfaça o interesse público que está a seu cargo prover. Com efeito, é tão somente a necessidade de cumprir esse dever que outorga ao Estado os poderes instrumentais que são indispensáveis a tal mister.

Assim, o Estado precisa exercitar o seu poder sempre em proveito da sociedade, porque se trata de um dever fazê-lo, não havendo qualquer espaço para exercitá-lo em função de sua vontade. O Estado deve interpretar a Constituição, em que se consubstanciou de forma positiva a vontade popular, para tomar a decisão que melhor atenda aos interesses da coletividade, à qual, em última análise, destina-se a adoção de alíquotas seletivas para o ICMS (FARIA, 2016, p. 150). Afinal, o poder discricionário nada mais pode ser do que o cumprimento do dever de alcançar a finalidade do Direito (MELLO, 2017, p. 15).

Nada obstante, é cediço que, a depender da forma segundo a qual o Direito regula determinada matéria, pode exsurgir para o Estado um campo de liberdade, maior ou menor, em que se verifique o denominado poder discricionário.

Nesse particular, o objetivo do presente estudo é tanto analisar como se dá a tributação de forma seletiva da energia elétrica, que ocupa uma posição de primeira necessidade no consumo da população em geral, por parte dos estados e do Distrito Federal, quanto verificar a possibilidade de o Poder Judiciário controlar a referida seletividade tributária. 


\section{O CONTROLE JURISDICIONAL DA DISCRICIONARIEDADE ESTATAL E A INDETERMINAÇÃO DO CONCEITO DE SELETIVIDADE}

No Direito, é comum haver situações em que se verifica um campo de liberdade interpretativo, em cujo interior cabe a interferência de uma apreciação subjetiva do intérprete quanto ao comportamento a ser tomado. Diz-se, então, que há discricionariedade (MELLO, 2017, p. 17).

$A b$ initio, insta que se destaque o fato de que a discricionariedade não se adscreve ao campo das opções administrativas efetuadas com base em critérios de conveniência e oportunidade, tema que concerne ao mérito do ato administrativo, mas envolve, igualmente, o tema da intelecção dos conceitos indeterminados (MELLO, 2017, p. 27-28). Demais disso, deve-se lembrar de que a eventual indeterminação dos enunciados normativos não se traduz em uma indeterminação aplicativa dos mesmos, conforme será demonstrado.

Logo, a presente questão envolve tanto uma opção fundada em conveniência e oportunidade quanto um conceito indeterminado. Para verificar se a alíquota estabelecida é conveniente e oportuna segundo o Direito Tributário, impõe-se a prévia discussão acerca da aplicabilidade ou não do conceito constitucional de seletividade.

O Direito, em geral, e o Direito Tributário, em especial, visam a garantir e a proteger a segurança jurídica no contexto das relações intersubjetivas em sociedade. Essa é a realidade do Estado de Direito, organizado segundo o sistema jurídico, composto por órgãos independentes, autônomos e hierarquizados, dotado das funções legislativa, executiva e judiciária que se exercem por intermédio de órgãos, ou poderes, distintos e harmônicos entre si (FARIA, 2016, p. 54).

Não se põe em dúvida o fato de que, no Estado de Direito, o Estado encontra-se completamente submetido aos parâmetros do sistema jurídico, especialmente os da Constituição de 1988, de modo que a atuação estatal seja sempre secundum legem (FARIA, 2016, p. 42-3; MELLO, 2017, p. 11).

Compete, pois, ao Legislativo, sempre conforme as balizas constitucionais, editar as leis tributárias que deverão ser aplicadas pelo Executivo e guiar a atividade do Poder Judiciário voltada à resolução das controvérsias que porventura surjam a propósito de sua aplicação válida. Assim, não cabe mais ver a discricionariedade como uma insubmissão ou não submissão da atividade estatal à normatividade constitucional (BINENBOJM, 2014, p. 19).

De todo modo, cumpre analisar primeiro como se dá a tributação da energia elétrica, que ocupa uma posição de primeira necessidade no consumo da população em geral, por parte dos estados e do Distrito Federal. 
Embora os estados e o Distrito Federal possuam disposições símiles em suas respectivas legislações tributárias, o presente estudo tomará como parâmetro para sua análise apenas a legislação do estado de Minas Gerais, mais especificamente a Lei Estadual nº 6.763, de 26 de dezembro de 1975, e o Decreto Estadual n 43.080, de 13 de dezembro de 2002 (MINAS GERAIS, 1975, 2002). Ambos em vigor, esses atos normativos são responsáveis pela consolidação da legislação tributária do estado e pela regulamentação do ICMS, respectivamente.

O estado de Minas Gerais exercitou sua competência constitucional e instituiu o ICMS, conforme o art. $3^{\circ}$, inciso I, da Lei $n^{0}$ 6.763/1975. Seguindo a linha da Constituição de 1988, consignou de forma expressa que o imposto poderá ser seletivo em função das mercadorias que tributará, nos termos do art. $5^{\circ}, \S 2^{\circ}$, da referida lei estadual. Considerando-se as alíquotas efetivamente estabelecidas pelo legislador estadual nos artigos 12 e 12-A da Lei $n^{\circ}$ 6.763/1975, podese afirmar que a seletividade do ICMS foi adotada pelo estado e, por conseguinte, deverá ser observada.

É dizer, ao estabelecer alíquotas diferentes, o legislador criou para si o dever de prever o percentual maior para o produto supérfluo, e o menor para o essencial.

Todavia, embora a energia elétrica ocupe posição de primeira necessidade no consumo da população em geral - fato incontestável -, a sua tributação pelos estados e pelo Distrito Federal é realizada por meio de ICMS com alíquotas elevadas, não raramente as mais elevadas em suas respectivas legislações.

Em Minas Gerais, a alíquota aplicável à tributação da energia elétrica adquirida dependerá de sua destinação. Por exemplo, se for para o consumo residencial, será tributada a uma alíquota de 30\%, nos termos do art. 12, inciso I, alínea 'g.2', da Lei nº 6.763/1975 (MINAS GERAIS, 1975). Essa alíquota é a segunda mais elevada da legislação mineira ${ }^{1}$, sendo igualmente aplicável apenas a bebidas alcoólicas (art. 12, inciso I, alínea 'g.1', da Lei nº 6.763/1975), de modo que supera as alíquotas que incidem sobre a maior parte das mercadorias tributadas pelo ICMS no estado: fogos de artifício, perfumes e joias, por exemplo, são tributados à alíquota de 25\%, conforme o artigo 12, inciso I, alínea 'a', combinado com a Tabela F, itens 4, 6 e 8 (respectivamente), ambos da Lei nº 6.763/1975 (MINAS GERAIS, 1975).

Se a energia elétrica for destinada para atividades rurais da área mineira da Superintendência de Desenvolvimento do Nordeste (Sudene) e o consumo for igual ou inferior a 100 quilowatts-hora

1 Atualmente, a alíquota mais elevada do ICMS no Estado de Minas Gerais é de 31\%, sendo aplicável às operações envolvendo o consumo de gasolina para fins carburantes e de solvente, conforme o artigo 12, inciso I, alínea ' $h$ ', da Lei $n^{\circ}$ 6.763/1975 (MINAS GERAIS, 1975). 
(kWh) mensais, e se tratar de operação interna, a lei autoriza o Executivo a reduzir a carga tributária para até zero, e, na hipótese de consumo superior a 100 kWh mensais, para até 12\%, conforme o art. 12, § 18, da Lei ${ }^{\circ}$ 6.763/1975 (MINAS GERAIS, 1975). Por último, se for destinada a atividades de irrigação desenvolvidas por produtores rurais fora da referida área da Sudene, o Executivo está autorizado a reduzir a carga tributária incidente sobre as operações com energia elétrica para 12\%, no período diurno, e para 7\%, no período noturno, conforme disposto no art. 12, § 22, da Lei $n^{\circ}$ 6.763/1975 (MINAS GERAIS, 1975).

Todavia, verificam-se três problemas na legislação mineira mencionada, todos eles relativos à concretização do princípio da seletividade.

Em primeiro lugar, a energia elétrica, por se tratar de uma única mercadoria, não poderia ter alíquotas diversas a depender da sua destinação concreta, mas, sim, uma só alíquota. Isso se deve ao fato de que a seletividade deve levar em consideração a mercadoria, e tão somente ela, relevando quaisquer outros fatores, como a sua destinação e a sua origem, na medida em que a sua vinculação é apenas para com a essencialidade do produto, por força da Constituição da República de 1988 (SCHOUERI, 2018, p. 419).

Em segundo lugar, as mercadorias essenciais devem ser, necessariamente, menos tributadas do que as supérfluas. Eis a razão de ser da seletividade tributária.

Seguramente, a previsão constitucional da seletividade não goza de indisputável objetividade, comportando intelecções diferentes a seu respeito. Na medida em que se trata de um conceito fluido ou indeterminado, que aponta para uma realidade suscetível de existir em graus e medidas variáveis, é possível que se divirja a respeito de sua configuração efetiva ou não na realidade (DI PIETRO, 2018, p. 248; MELLO, 2017, p. 19).

Todavia, conquanto a Constituição da República de 1988, de fato, não tenha definido o que se deve considerar essencial, a identificação de uma mercadoria essencial independe de escolha: ou a mercadoria é essencial ou não o é. Em virtude de ser de fácil apreensão, tome-se, a título de empréstimo, o exemplo oferecido por Sacha Calmon Navarro Coêlho, de que "feijão é gênero de primeira necessidade, e caviar é supérfluo” (COÊLHO, 2015, p. 326). Chega-se, assim, à conclusão de que não há a concorrência da subjetividade estatal na construção do conceito de essencial.

Destarte, o Estado não goza do poder de eleger, segundo critérios de conveniência e oportunidade, as mais diferentes providências à sua concretização, porquanto é possível compreendêla e dimensioná-la à luz do sistema jurídico em sua totalidade. A interpretação deve ser realizada tendo em vista o plexo total de normas jurídicas, especialmente quando se trata de conceitos indeterminados, os quais exigem essa interpretação contextual (MELLO, 2017, p. 30). 
Desse modo, é possível verificar, a partir do conjunto de mercadorias tributadas e de suas respectivas alíquotas, se a interpretação do legislador ou do administrador em relação à essencialidade daquelas está ou não adequada ao Direito e, se não estiver, o contribuinte poderá recorrer ao Judiciário a fim de retificar a situação.

Ignorar os limites do ordenamento jurídico que se impõem implica um agir arbitrário (GOMES, 2010, p. 44), de modo que a possibilidade de seu controle pelo Judiciário, para reparar a violação ao Direito, é patente, nos termos do art. 5 XXXV, da Constituição de 1988, especialmente no tocante à essencialidade, que se trata de questão de interpretação jurídica e não de efetiva discricionariedade, a qual suporia um campo de liberdade decisória para o Estado. Em outros termos, cuida-se de pura e simples aplicação da norma constitucional.

Além de ser possível recorrer ao Judiciário diante da violação ao mandamento constitucional, é necessário fazê-lo quando se tem em consideração o fato de que a seletividade representa uma forma de concretização do princípio da capacidade contributiva, relacionando-se, pois, com a proteção de direitos fundamentais, especialmente o da propriedade privada, e de valores constitucionais objetivos. Trata-se de uma questão juridicamente sensível, a qual deve se submeter ao controle judicial não deferente (JORDÃO, 2016, p. 79).

Ademais, a noção de insindicabilidade dos atos estatais emanados em função de conceitos imprecisos, inclusive os atos legislativos e administrativos, tem se esvaído progressivamente após a Constituição da República de 1988 (DI PIETRO, 2018, p. 249; FARIA, 2016, p. 228).

Em todo caso, não se está a negar que o estado disponha de certa margem de liberdade, a qual representa limite ao controle jurisdicional, no tocante ao estabelecimento da alíquota do ICMS. O estado, ao exercer sua competência tributária, pode ou não adotar alíquotas variadas. Em outras palavras, seria constitucional se o estado decidisse tributar todas as mercadorias a uma mesma alíquota.

Entretanto, saber se as alíquotas estabelecidas são fruto de uma liberdade intelectiva ou volitiva do legislador não importa, porque, em razão de uma ou de outra, os efeitos jurídicos não se alteram (MELLO, 2017, p. 25). O que importa é conclusão de que o Poder Judiciário poderá, sim, verificar se a seletividade foi respeitada no momento de determinação do aspecto quantitativo da regra-matriz de incidência do ICMS, mas não poderá ir além disso e determinar a alíquota que a respeitaria.

A título de exemplo, essa é a linha defendida por Hugo de Brito Machado (2008) no tocante à definição da margem de liberdade de que o legislador ordinário dispõe nesse particular. Segundo ele, sua amplitude “é apenas aquela que geralmente existe no fenômeno da concreção jurídica. Não 
se trata de poder discricionário. Trata-se de liberdade que decorre simplesmente da vagüidade dos conceito [sic] utilizados nas normas. Liberdade que está, sem dúvida, submetida ao controle judicial” (MACHADO, 2008, p. 51).

O Judiciário deve garantir que o Estado atue validamente, isto é, dentro dos limites que a lei lhe proporciona e segundo os parâmetros do sistema jurídico. Portanto, no Estado Democrático de Direito, impõe-se a possibilidade de controle do ato (BARROSO, 2018, p. 536), em função da própria previsão constitucional do princípio da seletividade, que se dirige a todos os envolvidos na sua concretização, inclusive o Poder Judiciário, autorizando-o a controlar o alcance da expressão constitucional (MACHADO, 2008, p. 53).

Nas palavras de Aliomar Baleeiro (2013), a concretização da seletividade exige do legislador aquilo que o autor denomina de "discricionarismo honesto”, o qual, “fiel ao espírito da Constituição, fará a seleção das mercadorias e a relatividade das alíquotas” (BALEEIRO, 2013, p. 490). Assim, esse critério de seletividade deverá observar a essencialidade da mercadoria.

Uma mercadoria será essencial de acordo com o seu grau de adequação à vida da maior parcela dos contribuintes brasileiros (BALEEIRO, 2013, p. 491). Afinal, a discricionariedade deve se adequar ao direto positivo e não o contrário, mormente porquanto o eixo metodológico de todo o Direito Público, no qual se insere o Direito Tributário, gira em torno da ideia de dever (MELLO, 2017, p. 14).

Por isso, Sacha Calmon Navarro Coêlho (2015, p. 326) acertadamente afirma que “o conceito de mercadoria supérflua não fica ao alvedrio do legislador. Adotada que seja a seletividade, tem o contribuinte o direito de provocar o Judiciário para que declare, à luz de critérios técnicos e dos aspectos sociais da Nação, se esta ou aquela mercadoria é supérflua”.

Sem dúvida, a energia elétrica ocupa uma posição de primeira necessidade no consumo da população em geral, independentemente da riqueza individual. Ela não poderia ter sido considerada pela legislação mineira como equiparável a bebidas alcoólicas e menos essencial, ou mais supérflua, do que fogos de artifício e joias. Qualquer conclusão em sentido diverso seria prontamente rechaçada não só pela técnica jurídica, mas mesmo pelo senso comum.

Ademais, a ratificar a não superfluidade da energia elétrica, estão o art. 21, inciso XII, alínea 'b’, da Constituição de 1988, que qualifica a prestação do serviço de fornecimento de energia elétrica como serviço público de competência da União, e a Lei n ${ }^{\circ}$ 9.074/1995, que regula a forma segundo a qual essa prestação, em regime de concessão administrativa, será realizada.

Há previsão legal expressa sobre a essencialidade da energia elétrica no art. 10, inciso I, da Lei 7.883/1989. Ao definir as atividades essenciais e regular o atendimento das necessidades 
inadiáveis da comunidade, o legislador elencou, entre elas, a produção e a distribuição de energia elétrica.

Juridicamente e na prática, isso significa que os sindicatos, os empregadores e os trabalhadores ficam obrigados a garantir, mesmo durante o exercício do direito constitucional de greve, a prestação dos serviços indispensáveis ao atendimento das necessidades inadiáveis da comunidade, essas entendidas como as que, se não atendidas, implicariam perigo iminente à sobrevivência, à saúde ou à segurança da população, conforme disposto no art. 11, parágrafo único, da Lei ${ }^{0} 7.883 / 1989$ (BRASIL, 1989).

Ainda em favor da tese da essencialidade da energia elétrica para a população brasileira, pode-se mencionar o Programa Nacional de Universalização do Acesso e Uso da Energia Elétrica, também conhecido como “Luz para Todos”.

Instituído pelo Decreto ${ }^{\circ}$ 4.873, de 11 de novembro de 2003, esse programa do Governo Federal tratava de uma política pública destinada a propiciar, até o ano de 2011, o atendimento em energia elétrica à parcela da população do meio rural brasileiro que ainda não possui acesso a esse serviço público (BRASIL, 2003).

Embora esteja além do objetivo do presente estudo, cumpre ressaltar que, não tendo o Governo Federal conseguido atingir o objetivo da universalização desse direito no referido prazo, criou-se um plano de ação a fim de alcançar as famílias que vivem no meio rural e ainda são desprovidas de energia elétrica.

Destarte, considerar como supérfluo um serviço público cuja disponibilidade é considerada essencial e inadiável à sociedade por disposição legal expressa, e que ainda consiste em uma política de Estado, representaria uma contradictio in terminis.

Então, se o arroz e o feijão, mercadorias essenciais, são tributados pelo ICMS à alíquota de 12\%, nos termos do art. 12, inciso I, alínea ‘b.1’, da Lei nº 6.763/1975 (MINAS GERAIS, 1975), por que a energia elétrica deveria sê-lo à de 30\%, assim como as bebidas alcoólicas? A discriminação negativa operada pela legislação mineira em relação à incidência do ICMS sobre a energia elétrica não se sustenta perante a Constituição de 1988.

Em terceiro e último lugar, a autorização que o Legislativo deu ao Executivo em Minas Gerais para reduzir a carga tributária em determinadas hipóteses não parece juridicamente sustentável no ordenamento jurídico pátrio.

O Direito Tributário é regido pelo princípio da legalidade. Com assento no texto constitucional, nos art. $5^{\circ}$, inciso II, e 150, inciso I, a legalidade da tributação proscreve a delegação da função legislativa, salvo nos casos expressamente excetuados pela própria Constituição, exigindo 
lei em sentido formal e material para dispor sobre os elementos essenciais da regra-matriz de incidência tributária.

As exceções estão previstas nos art. $153, \S 1^{\circ}, 155$, § $4^{\circ}$, inciso V e 177 , $\S 4^{\circ}$, inciso I, alínea 'b', do texto constitucional, referindo-se ao imposto de importação (II), ao imposto de exportação (IE), ao IPI, ao imposto sobre operações financeiras (IOF), ao ICMS-combustíveis e à CIDEcombustíveis. Entre elas, não se encontra o ICMS.

A fim de esclarecer o conteúdo constitucional dessa exigência, o art. 97 do Código Tributário Nacional, em seu inciso IV, explicita que somente a lei pode estabelecer, por exemplo, “a fixação de alíquota do tributo e da sua base de cálculo” (BRASIL, 1966), ou seja, está proibida a delegação da competência legislativa, em função do princípio da legalidade.

Nas palavras de Sacha Calmon Navarro Coêlho (2015, p. 212, grifo do autor), “de nada adiantaria, já descontadas as exceções, a Constituição reservar à lei o trato de determinada matéria se, depois, o legislador, fazendo dela tábula rasa, delegasse o seu manejo ao administrador. Seria o dito pelo não dito. A Constituição obriga o legislador a consentir a tributação”.

Assim, ainda que se admita a possibilidade de delegação no caso concreto (o que se faz tão somente ad argumentandum tantum), porque a alteração em questão dar-se-ia nos limites concedidos pelo Legislativo, o Estado não pode utilizar-se de seus poderes indiscriminadamente, da maneira que mais lhe apeteça, para a prática de um ato que, a seu grado, intente expedir (MELLO, 2017, p. 60).

A Administração Pública, incluída, certamente, a Administração Tributária, só pode atuar conforme a lei, à qual está estritamente subordinada em uma relação de não contradição e de subsunção (MELLO, 2017, p. 13). No caso de Minas Gerais, em que a lei outorga o poder de reduzir a carga tributária em alguns casos, a Administração só pode mobilizar tal poder ante determinadas circunstâncias, em vista de específicos fins e por meio de certas formas (MELLO, 2017, p. 61). Afinal, a busca pelo interesse público, já o disse Bandeira de Mello (2017, p. 70), não justifica o pisoteamento de outros direitos igualmente confortados no sistema normativo, como é o caso do princípio da seletividade.

Desse modo, o Executivo carece de discricionariedade para utilizar-se dela livremente, de modo a reduzir a carga tributária de uma determinada mercadoria. Ao fazê-lo, a Administração não pode ignorar a exigência constitucional de seletividade, devendo, pois, analisar todas as alíquotas de todas as mercadorias objeto da legislação estadual, a fim de assegurar a coerência e consistência da seletividade da tributação.

Por exemplo, se o Executivo mineiro fez uso da autorização constante do art. 12, § 22, da Lei $n^{\circ} 6.763 / 1975$, reduzindo a carga tributária, nas operações com energia elétrica envolvendo 
atividades de irrigação desenvolvidas por produtores rurais fora da área da Sudene, para 12\% no período diurno e para 7\% no período noturno, ele não poderá, concomitantemente, utilizar-se da autorização contida no art. 12, § 31, da Lei ${ }^{0}$ 6.763/1975 para reduzir a 7\% a carga tributária nas operações internas com iogurte ou com queijo petit suisse (MINAS GERAIS, 1975). Fazê-lo feriria o princípio da seletividade na sistemática do ICMS e, por conseguinte, seria inconstitucional.

Todas essas questões podem ser levadas ao Judiciário e submetidas ao seu controle. Isso de fato ocorreu, e um contribuinte impugnou a tributação a que estava sujeito por força da legislação do estado de Santa Catarina - algo cuja discussão básica será examinada no item seguinte.

\section{A TRIBUTAÇÃO DO CONSUMO DE ENERGIA ELÉTRICA E O RECURSO EXTRAORDINÁRIO No 714.139-SC}

A controvérsia relativa à tributação, pelo ICMS, do fornecimento de energia elétrica e da prestação de serviços de telecomunicação e à seletividade desse imposto teve a sua repercussão geral, econômica e social, reconhecida pelo STF no Recurso Extraordinário (RE) $n^{0}$ 714.139-SC, sob a relatoria do ministro Marco Aurélio Mello. Trata-se do tema ${ }^{0} 745$ da repercussão geral do STF².

Nesse processo, ao STF competirá decidir sobre a (in)constitucionalidade de uma norma estadual que estabeleceu alíquota superior à genérica para tributar as referidas operações. No caso concreto, enquanto a maior parte das operações que compõem o aspecto material do referido imposto sobre o consumo é tributada a uma alíquota de 17\%, o fornecimento de energia elétrica e a prestação de serviços de telecomunicação o são a 25\%, uma alíquota 47\% superior.

O Tribunal de Justiça do Estado de Santa Catarina (TJSC) decidiu pela constitucionalidade do art. 19, inciso I, alínea 'a', da Lei Estadual nº 10.297/1996, prevendo a alíquota de 25\% relativa ao ICMS incidente sobre o fornecimento de energia elétrica e os serviços de telecomunicação, em patamar superior ao estabelecido para as operações em geral, cuja alíquota é de 17\%.

Para sustentar essa conclusão, o TJSC aduziu dois fundamentos principais. O primeiro foi o de que não haveria qualquer vício no tratamento diferenciado em questão, mesmo consideradas as mencionadas alíquotas geral e específica do ICMS catarinense.

Em síntese, o tribunal a quo entendeu que não teria havido violação ao princípio da seletividade em função da essencialidade dos produtos em questão, conforme trata o art. 155, § $2^{\circ}$,

2 Em 13/06/2014, o STF, por maioria, reputou constitucional a questão, tendo sido vencidos os ministros Teori Zavascki, Rosa Weber, Cármen Lúcia e Dias Toffoli. Também por maioria, reconheceu a existência de repercussão geral da questão constitucional suscitada, vencidos os ministros Teori Zavascki, Ricardo Lewandowski, Rosa Weber, Cármen Lúcia, Roberto Barroso e Dias Toffoli. Não se manifestaram os ministros Celso de Mello e Joaquim Barbosa. 
inciso III, da Constituição da República, porque a norma constitucional envolveria "uma faculdade e não uma imperatividade”, isto é, uma alternativa à disposição da discricionariedade do intérprete.

Ademais, o segundo fundamento considerou que o legislador teria observado a indispensabilidade da energia elétrica para a sociedade e, em função disso, por meio da instituição de alíquota superior, teria buscado "desestimular o consumo justamente nos setores onde ele é mais elevado, bem como evitar o desperdício e, consequentemente, as interrupções na distribuição” (BRASIL, 2014).

Conquanto esposada pela Fazenda Pública catarinense, essa interpretação do enunciado constitucional, por todo o exposto, não se mostra acertada.

Com efeito, o Superior Tribunal de Justiça (STJ), por exemplo, admite que a previsão do art. 155, § $2^{\circ}$, III, da Constituição de 1988 seria apenas uma possibilidade em relação ao ICMS. É dizer, o legislador estadual, diferentemente do que ocorreria em relação ao IPI, gozaria de uma margem de discricionariedade muito maior no tocante à sua adoção e, portanto, aplicação. A previsão, no entanto, não seria absoluta.

Mesmo considerando não ser obrigatória a seletividade do imposto, deve-se extrair do respectivo comando constitucional norma no sentido de que, adotadas alíquotas diversas pelo legislador estadual, a discriminação deve ser, obrigatoriamente, orientada pelo critério da seletividade. Em outras palavras, ao estabelecer alíquotas diversas, o legislador aceitou para si próprio o dever de prever o percentual maior para a mercadoria supérflua e o menor para a essencial (MACHADO, 2008, p. 50).

O texto constitucional não consiste em mera recomendação. Com isso, está-se a dizer que ele é imperativo, como o é todo o Direito, de modo que quaisquer previsões tocantes à seletividade que envolvam o ICMS devem estar condicionadas ao caráter essencial do bem ou do serviço por ele tributado, e tão somente a ele. Assim, ambos os fundamentos subvertem a lógica da seletividadeessencialidade constitucional.

Nenhuma pessoa há de discutir se tratar de um absurdo a legislação prever alíquota de 17\% para operações de venda de bens como brinquedos, joias e fogos de artifício e outra de 25\% para incidir sobre o fornecimento de energia elétrica e os serviços de telecomunicação.

Por isso, no RE nº 714.139-SC, a Procuradoria-Geral da República (PGR) emitiu parecer a favor do contribuinte, pela inconstitucionalidade da legislação do estado de Santa Catarina, na medida em que as alíquotas por ela atribuídas à tributação, pelo ICMS, do fornecimento de energia elétrica e da prestação de serviços de telecomunicação violariam a seletividade do ICMS por não respeitar a essencialidade deles. 
Não compete ao Legislativo nem ao Executivo definir livremente a forma de realizar a seletividade tributária. Não há discricionariedade nesse sentido: ou se está a realizar a seletividade ou não. Tertium non datur. De todo modo, resta aguardar a definição da matéria pelo STF.

\section{CONSIDERAÇÕES FINAIS}

Ao tributar o consumo da população, o Estado obtém os recursos de que necessita para satisfazer os interesses da sociedade, destacando-se, nesse particular, o ICMS, que incide sobre a comercialização de energia elétrica, dentre outras manifestações de riqueza.

Na prática, verifica-se que o ICMS incide sobre o consumo de energia elétrica com alíquotas elevadas em todo o País, as quais superam, em regra, as alíquotas relativas às demais mercadorias igualmente tributadas pelo referido imposto. Diante dessa realidade, impõe-se cotejá-la com a Constituição da República de 1988, que define as características fundamentais do ICMS.

Entre as características constitucionais que delineiam a base do ICMS e devem ser observadas pela legislação complementar e pela legislação interna dos entes federados na sistematização desse imposto, encontra-se a seletividade em função da essencialidade da mercadoria a ser tributada, nos termos do art. 155, § $2^{\circ}$, inciso III (BRASIL, 1988), conforme analisado adrede.

Uma vez aceita a seletividade para o ICMS, as principais questões em torno da tributação. pelo ICMS, do consumo de energia elétrica, analisadas no presente estudo, passam a consistir na intelecção do conceito de essencialidade pelo Estado - este entendido como o ente tributante no exercício da função de estabelecer seletividade para a incidência do ICMS -, que não pode ignorar a exigência constitucional de seletividade e deve assegurar a coerência e consistência da seletividade da tributação, e na possibilidade de o Judiciário controlá-la.

Verificou-se que a indeterminação do enunciado constitucional não se traduz em indeterminação aplicativa dele, porque a identificação de uma mercadoria essencial independe da escolha subjetiva do intérprete, e, no tocante à energia elétrica, a sua essencialidade se expressa pela posição de primeira necessidade no consumo da população em geral, sendo possível compreendê-la e dimensioná-la à luz da realidade jurídica brasileira.

Ademais, observou-se que as legislações estaduais tendem a não observar a seletividade tributária conforme exige a Constituição da República de 1988. Isso porque, no momento da instituição do ICMS pelos estados federados, a essencialidade das mercadorias e dos serviços tributáveis não tem sido determinante para o dimensionamento das alíquotas aplicáveis, que se mostram, pois, inconstitucionais. 
Afirma-se que a energia elétrica, por se tratar de uma única mercadoria essencial, não poderia ter alíquotas diversas a depender da sua destinação concreta, mas, sim, apenas uma só alíquota, e deve ser, necessariamente, menos tributada do que as demais mercadorias que, em relação a ela, sejam supérfluas ou menos essenciais.

Desse modo, resta confirmada a hipótese, adotada pelo presente trabalho, de que o mandamento constitucional da seletividade-essencialidade não tem sido devidamente observado pelas legislações do referido imposto estadual tais como atualmente postas. Isso porque, não obstante tenha aceitado para si próprio o dever de prever o percentual maior para a mercadoria supérflua e o menor para a essencial ao estabelecer alíquotas diversas para a sistemática do ICMS, o Estado não o cumpre na prática, de modo que o contribuinte está autorizado a recorrer ao Poder Judiciário.

Tal autorização decorre do fato de que, a fim de assegurar a higidez da ordem jurídica, a Constituição da República outorga ao Judiciário não apenas a competência, mas também o dever de apreciar a questão, a fim de afastar do ordenamento jurídico a lei inconciliável com a exigência constitucional da seletividade.

Por todo o exposto, a pesquisa realizada leva à conclusão de que o Judiciário deve garantir a imperatividade do texto constitucional no tocante à concretização da seletividade relativa ao ICMS incidente sobre a energia elétrica, assegurando que o Estado aja dentro dos limites e segundo os parâmetros da ordem jurídica. In concreto, essa controvérsia, ora analisada, deverá ser decidida pelo STF no RE $n^{\circ}$ 714.139-SC, cujos autos se encontram conclusos ao ministro Relator Marco Aurélio Mello após a juntada de parecer, favorável ao contribuinte, emitido pela PGR.

A conclusão alcançada é importante, na medida em que, ainda hoje, parte da doutrina e do Judiciário vincula à imprecisão dos conceitos a existência de poder discricionário, de modo que diversos atos, embora inválidos, acabam sendo considerados insindicáveis e, por conseguinte, subsistindo equivocadamente na ordem jurídica. No Estado Democrático de Direito, o Judiciário pode e deve controlar atos normativos expedidos em torno de conceitos jurídicos indeterminados, como o da seletividade.

\section{REFERÊNCIAS}

BALEEIRO, Aliomar. Direito Tributário Brasileiro. Atualizada por Misabel Abreu Machado Derzi. 12. ed. Rio de Janeiro: Forense, 2013.

BALEEIRO, Aliomar. Limitações Constitucionais ao Poder de Tributar. Atualizada por Misabel Abreu Machado Derzi. 8. ed. Rio de Janeiro: Forense, 2010. 
BARROSO, Luís Roberto. Curso de Direito Constitucional Contemporâneo: os conceitos fundamentais e a construção do novo modelo. 7. ed. São Paulo: Saraiva, 2018.

BINENBOJM, Gustavo. Poder de polícia, ordenação, regulação: transformações políticojurídicas, econômicas e institucionais do direito administrativo ordenador. 2. ed. Belo Horizonte: Fórum, 2017.

BINENBOJM, Gustavo. Uma teoria do direito administrativo: direitos fundamentais, democracia e constitucionalização. 3. ed. Rio de Janeiro: Renovar, 2014.

BRASIL. Congresso Nacional. Constituição da República Federativa do Brasil, de 05 de outubro de 1988. Diário Oficial [da] República Federativa do Brasil, Poder Executivo, Brasília, DF, 05 de outubro de 1988. Seção 1. p. 1. Disponível em: http://www.in.gov.br. Acesso em: 15 nov. 2018.

BRASIL. Congresso Nacional. Decreto $n^{\circ} 4.873$, de 11 de novembro de 2003. Institui o Programa Nacional de Universalização do Acesso e Uso da Energia Elétrica - "LUZ PARA TODOS” e dá outras providências. Diário Oficial [da] República Federativa do Brasil, Poder Executivo, Brasília, DF, 12 de novembro de 2003. Seção 1. p. 130. Disponível em: http://www.in.gov.br. Acesso em: 26 nov. 2018.

BRASIL. Congresso Nacional. Lei $n^{0}$ 5.172, de 25 de outubro de 1966. Dispõe sobre o Sistema Tributário Nacional e institui normas gerais de direito tributário aplicáveis à União, Estados e Municípios. Diário Oficial [da] República Federativa do Brasil, Poder Executivo, Brasília, DF, 27 de outubro de 1966. Seção 1. p. 12.452. Disponível em: http://www.in.gov.br. Acesso em: 26 nov. 2018.

BRASIL. Congresso Nacional. Lei $n^{\circ}$ 7.783, de 28 de junho de 1989. Dispõe sobre o exercício do direito de greve, define as atividades essenciais, regula o atendimento das necessidades inadiáveis da comunidade, e dá outras providências. Diário Oficial [da] República Federativa do Brasil, Poder Executivo, Brasília, DF, 29 de junho de 1989. Seção 1. p. 10.561. Disponível em: http://www.in.gov.br. Acesso em: 26 nov. 2018.

BRASIL. Ministério da Fazenda. Secretaria da Receita Federal. Carga tributária no Brasil - 2016: Análise por Tributos e Bases de Incidência. Brasília: MF, 2017. Disponível em: https://bit.ly/3mCNuWv. Acesso em: 19 nov. 2018.

BRASIL. Supremo Tribunal Federal. Acórdão. RE n. 714.139/SC. Recorrente: Lojas Americanas S/A. Recorrido: Estado de Santa Catarina. Relator: Min. Marco Aurélio. Brasília, DF, 12 de junho de 2014. Diário da Justiça [da] República Federativa do Brasil, Brasília, DF, 26 set. 2014. Disponível em: http://www.stf.jus.br. Acesso em: 26 dez. 2018.

COÊLHO, Sacha Calmon Navarro. Curso de Direito Tributário Brasileiro. 14. ed. Rio de Janeiro: Forense, 2015.

DI PIETRO, Maria Sylvia Zanella. Direito Administrativo. 31. ed. Rio de Janeiro: Forense, 2018.

FARIA, Edimur Ferreira de. Controle do mérito do ato administrativo pelo Judiciário. 2. ed. Belo Horizonte: Fórum, 2016. 
GOMES, Marcus Lívio. A interpretação da legislação tributária: instrumentos para a unificação de critério administrativo em matéria tributária. São Paulo: Quartier Latin, 2010.

JORDÃO, Eduardo. Controle Judicial de uma Administração Pública Complexa: a experiência estrangeira na adaptação da intensidade do controle. São Paulo: Malheiros, 2016.

KIRCHHOF, Paul. Tributação no Estado Constitucional. Tradução Pedro Adamy. São Paulo: Quartier Latin, 2016.

MACHADO, Hugo de Brito. O ICMS no fornecimento de energia elétrica: questões da seletividade e da demanda contratada. Revista Dialética de Direito Tributário, São Paulo, n. 155, p. 48-56, ago. 2008.

MELLO, Celso Antônio Bandeira de. Discricionariedade e controle jurisdicional. 2. ed. 17. tir. São Paulo: Malheiros, 2017.

MINAS GERAIS. Secretaria de Estado da Fazenda. Decreto $\mathbf{n}^{\mathbf{0}} \mathbf{4 3 . 0 8 0}$, de 13 de dezembro de 2002. Altera o Regulamento do ICMS, aprovado pelo e dá outras providências. Belo Horizonte, Minas Gerais, 13 dez. 2002. Disponível em: https://bit.ly/3mDtcvW. Acesso em: 19 nov. 2018.

MINAS GERAIS. Secretaria de Estado da Fazenda. Lei nº 6.763, de 26 de dezembro de 1975. Consolida a Legislação Tributária do Estado de Minas Gerais e dá outras providências. Belo Horizonte, Minas Gerais, 30 dez. 1975. Disponível em: https://bit.ly/3lG2Ckm. Acesso em: 19 nov. 2018.

SCHOUERI, Luís Eduardo. Direito Tributário. 8. ed. São Paulo: Saraiva, 2018.

SILVEIRA, Paulo Antônio Caliendo Velloso da. Direito Tributário e Análise Econômica do Direito: uma visão crítica. Rio de Janeiro: Elsevier, 2009.

TORRES, Ricardo Lobo. Tratado de Direito Constitucional Financeiro e Tributário: valores e princípios constitucionais tributários. 2. ed. v. 2. Rio de Janeiro: Renovar, 2014. 